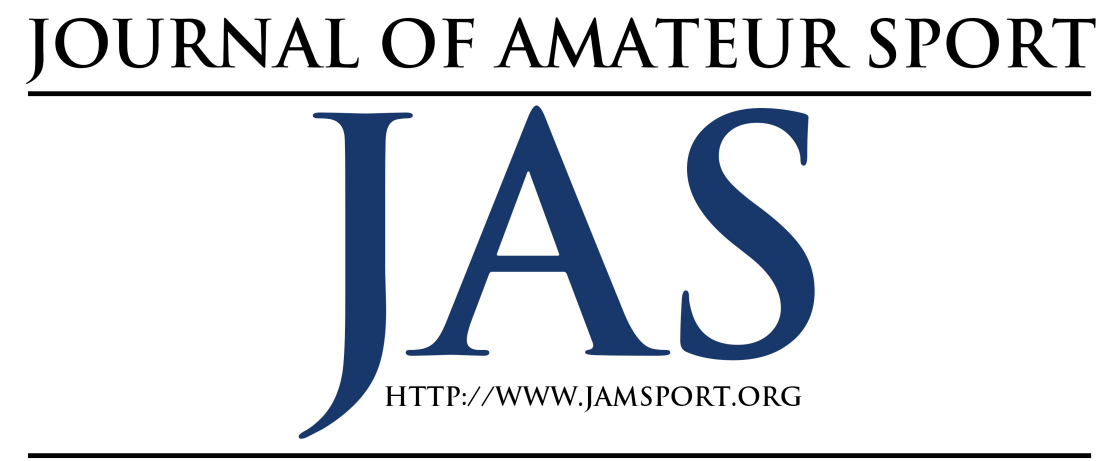

\title{
Health Culture and Running: Non-Elite Runners' Understandings of Doping and Supplementation
}

\author{
April D. Henning \\ National Development and Research Institutes
}

Participants at the non-elite level of road running often take up the sport for purposes of health, as a way of taking responsibility for their own well-being. Often, these runners use dietary supplements as a way to improve health and to potentially enhance running performance. Supplements are distinct from banned performance enhancing drugs (PEDs), as they are legal and widely available, though very loosely regulated. Research demonstrates that the line between supplements and banned PEDs is increasingly blurry as cases of cross-contaminated and mislabeled supplements continue to be found. Such products may pose health risks to unsuspecting consumers. Despite anti-doping agencies' warnings to elite runners about these risks, non-elite runners are rarely told by any sport or anti-doping body to be wary of supplements. They are, however, inundated with media coverage of doping scandals usually involving only a few of the substances banned in sport. In short, these runners are often left to navigate supplement use on their own and many conflate supplement availability with safety. This article explores these routine dietary supplement practices among non-elite runners. Drawing from interviews with 28 non-elite runners in New York City, I discuss the perceptions and understandings of doping and dietary supplement use within the context of health culture. Interview data reveal that the social acceptance of dietary supplements and their widespread use among the broader public reinforce the notion among non-elite runners that such products are objectively safe and healthy. I argue that based on their assumptions of supplement safety, non-elite runners view dietary supplements as distinctly different from PEDs and that this difference encourages their use as health and performance aids. 
$\mathrm{R}$ oad running is a continually growing sport, especially at the amateur or runners compete. In 2014, Running USA (2015) reported 18.75 million runners finished road races of all distances. This was a 1\% decrease from 2013. This year over year decline was rare, as road running participation increased by $300 \%$ between 1990 and 2013 (Running USA, 2015). Road races are unique from other sporting events in that the elite and non-elite racing fields run concurrently on the same course. It is the runners at non-professional levels of road racing-specifically those at the competitive, non-elite level—who are the focus of this article.

These runners exist within a healthicized context that increasingly links health and lifestyle choices with moralityhealthy individuals are good by virtue of the effort they put into their health, while unhealthy individuals are bad due to poor decision-making (Conrad, 1994). Running is one way to manifest a commitment to a healthy lifestyle and demonstrate making good choices - it acts as an enhancement to one's health. Evidence of running as a healthy lifestyle can be found in running magazines, such as Runner's World, and mainstream media, including the New York Times. These include reports of research studies demonstrating the ways running can keep us young (Reynolds, 2014; Roberts, 2015), that runners are generally healthier than non-runners (Hutchinson, 2015), and even that running has health benefits for runners' non-running spouses (Well, 2014). Running for wellness or fitness signals an individual has acknowledged an understanding of the risks of sedentary lifestyles and inactivity and the benefits it can confer, has accepted recommendations of health experts, and is taking responsibility for managing her or her own risk (Shipway \& Holloway, 2010; Shipway, Holloway, \& Jones, 2012). In this context, running shifts from pleasure or leisure to a process of health. This process is not necessarily focused around achieving a measurable racing outcome. Rather, health is a process that constantly pursues better health by accepting and applying recommendations of those that are considered experts on health or training.

While running may act as an enhancement to one's health, as a physical activity it may also be enhanced in a variety of ways. Runners have a range of choices for enhancing running, ranging from getting more sleep to cross-training to using dietary supplements to using banned performance enhancing drugs (PEDs). In this article, I use the term supplement in reference to all products included in the National Institutes of Health's (NIH) definition of a dietary supplement. The NIH defines dietary supplements using the four-part definition in the 1994 Dietary Health and Supplement Education Act. Accordingly, a dietary supplement "is intended to supplement the diet; contains one or more dietary ingredients (including vitamins; minerals: herbs or other botanicals; amino acids; and 
other substances) or their constituents; is intended to be taken by mouth as a pill, capsule, tablet, or liquid; and is labeled on the front panel as being a dietary supplement" (NIH, 2011). This definition includes vitamin and minerals in pill form, as well as athlete-oriented products such as electrolyte replenishing drinks and gels. Each of the available enhancement options may be more or less effective or efficient, yet runners do not necessarily view them based on their objective benefit to running. Within the healthicized context of running, individuals seek improvement with as little risk as possible, and decisions about enhancements have implications for their identities as health-seeking individuals. Any substance viewed as posing a risk to health, such as PEDs, is bad, while substances understood to promote health are good. However, this line between good and bad may be obscured through misunderstanding or incomplete information, marketing efforts, and the ways substances are regulated.

The line between what is allowed under anti-doping regulations and what is considered doping is increasingly blurred when considering dietary supplements. Most are legal and widely available, but unlike prescription products or banned substances, dietary supplements are not regulated in the U.S. (Cohen, 2012). Crosscontamination with substances not listed as ingredients-including those that are banned by anti-doping agencies - can make their way into common products found in local vitamin shops and pharmacies (Van Thuyne, Van Eenoo, \& Delbeke, 2006). Pipe and Ayotte (2002) reported that the lax regulation of supplements has led to many substances of "dubious value, content, and quality" (p. 245) becoming widely available to the consuming public, including athletes. Many mistakenly assume supplements are regulated as rigorously as prescription medications, a finding consistent with a 2002 nationwide Harris Poll that found 59\% of 1,010 respondents incorrectly believed the supplement industry was well-regulated by an agency such as the FDA (Harris Interactive, 2002). However, this mistaken view of supplements as safe and healthy leaves individuals who use them, including athletes, vulnerable to negative health outcomes from tainted or mislabeled products.

This article explores non-elite runners' views of routine dietary supplementation practices that do not necessarily fall under the definition of doping, but are encouraged within health culture. Here I discuss findings from interviews with non-elite runners about their views and understandings of PEDs and supplements with regard to health. I argue that based on their assumptions of supplement safety, non-elite runners view dietary supplements differently from PEDs and that this difference encourages their use as health and performance aids.

\section{Review of Literature}


Social scientists have noted the emergence of healthicization processes that forge a link between health and morality (Conrad, 1994). This "new health morality" (Becker, 1986 as cited in Conrad, 1994, p. 387) transforms health into a virtue, one that individuals in neoliberal societies are responsible for continuously working towards. Healthicization focuses on "lifestyle causes and behavioural interventions" (Williams, 2002, p. 85) to address social issues (i.e. cigarette smoking, obesity). Health is a goal that morally good members of society work towards through their personal choices and behaviors, guided by expert advice on the best ways to pursue health (Rose, 1999). To be healthy, individuals must constantly monitor their personal health risks in relation to their behaviors in order to make the obligatory correct choice (Rose, 1999). The result is a health culture wherein health is "both a goal and a source of anxiety, a value for self and others, integral to identity, a state of being that is continually assessed and the organizing concept for a vast organization of social action" (Crawford, 2006, p. 404).

As a result of healthicization processes, health and fitness have become increasingly commodified (Guthman \& DuPuis, 2006). Contemporary health culture is underpinned by the imperative to health and acceptance that one's health is constantly at risk (Crawford, 2006). Within this culture the health market for wellness and selfimprovement aids has expanded (Lavrence \& Lozanski, 2014). The growing health and fitness industries offer a vast array of health products and services available for purchase and consumption, including fitness clothing, exercise gear, health and fitness publications, and dietary supplements (Ayo, 2012). Many health products are aimed at addressing "needs" related to anxieties over one's risk for various maladies that consumers are told can be mitigated by proper health and lifestyle choices (Isin, 2004). These aids offer a type of health "insurance" to consumers through behavioral changes and lifestyle choices intended to reduce their risk of illness or otherwise poor health (Ayo, 2012, p. 103). The expectation that individuals will consume health and lifestyle products is largely based on the assumption that individuals will choose to engage in activities that promote their own wellbeing (Rose, 1999).

Running and the running body assume particular meanings in a healthicized context where morality is bound up with health and fitness. Running, as with other forms of movement, can be transformative (Hochstetler, 2007). Gillick (1984, p. 384) argues that, beginning in the 1960's, running has become a way of "shifting responsibility for environmental change from society to the individual, and of redefining 'being ill' as 'being guilty."' No longer simply a leisure pursuit, running has become a "health promotion activity" (Gillick, 1984, p. 383) that appealed "to the venerable notion of upright living as a means to personal and social renewal" (Gillick, 1984, p. 371). 
Running, an example of "upright living", is part of body projects through which the moral goodness of the selves that are "dedicated, controlled, disciplined, culturally and economically invested in health and are self-responsible" (Shipway \& Holloway, 2010 , p. 275) are reflected on the healthy and fit bodies of runners.

Athletes focus on making what they understand to be correct health choices and avoid risk. Runners consume products they believe will make them faster, stronger, and healthier. Chief among these products are dietary supplements, which are commonly used among the U.S. population (Gahache, Bailey, Burt, Hughes, Yetley, Dwyer, Picciano, McDowell, \& Sempos, 2011) but especially by athletes (Bailey, 2013; Baume, Hellemans, \& Saugy, 2007; Suzic Lazic, Dikic, Radivojevic, Mazic, Radovanovic, Mitrovic, Lazic, Zivanic, \& Suzic, 2011). Runners may view these choices as part of the process of being healthy (Henning, 2014). Dietary supplements do not carry the stigma of PEDs, which have been demonized as unhealthy, unethical, and immoral (López, 2013; WADA, 2015a). Choosing to use dietary supplements believed to offer performance or health enhancement is not necessarily based on the desire for a running-related outcome. Rather, it may be a choice that reflects the desire to pursue health by choosing the "healthy" alternative to PEDs.

Within our current health culture, the purchase and use of products to promote health—including dietary supplements—is not merely tolerated or accepted, it is encouraged (Lavrence \& Lozanski, 2014). Daily use of these products could be understood as demonstrating an individual's commitment to health, as does avoiding banned PEDs and their potential health risks, though supplement use does not necessarily indicate one's level of commitment. Regardless of their widespread use, some substances used or found in supplements have been banned in sport as doping agents.

\section{Regulation}

WADA is the body responsible for determining what constitutes doping in sport and for overseeing the testing and enforcement of athletes around the world through national-level agencies, including USADA. WADA relies on three-pronged criteria to determine if a substance should be banned: 1) its performance enhancing potential, 2) its actual or potential risk to athlete health, and 3) whether or not it violates the "spirit of the sport" (WADA, 2015a). If a substance meets two of the three criteria it is placed on WADA's annually updated List of Banned Substances (WADA, 2015b). Illustrating the healthicized context in which these regulations are enforced, athletes are held to the "strict liability" standard that states, "it is not necessary that intent, Fault, negligence, or knowing Use on the Athlete's part be demonstrated by the Anti-Doping Organization in order to establish an anti-doping rule violation" 
(WADA, 2015a). Athletes are responsible for whatever may be found in their system through an anti-doping test, regardless of how or why it is present.

Because the list is regularly altered and includes classes of substances (e.g. anabolic agents) as well as specific compounds (e.g. methyl-1-testosterone), athletes and other individuals may have difficulty navigating which substances are banned and where they may be found. Mottram, Chester, Atkinson, and Goode (2008) surveyed elite athletes on their knowledge of the current approach to banned substances and overthe-counter (OTC) products, finding that knowledge about what constitutes doping or an anti-doping violation varied greatly between the respondents. This variance existed despite their status as elites who are subject to both anti-doping efforts and education, and often have access to medical professionals who may offer guidance.

Research with elite female triathletes found many lacked an understanding of the principles and procedures underlying the anti-doping process (Johnson, Butryn, \& Masucci, 2013). Some of the misunderstandings around PEDs might be due to beliefs about certain types of drugs or modes of ingestion. For example, anabolic steroids and hGH are often thought to be used by bodybuilders to achieve an overly muscled aesthetic that is far outside the normative body type (Monaghan, 2001; Beamish, 2011). Additionally, injected drugs are linked to illicit drug users, a group widely considered deviant, and those who use heroin and crack-also associated with poorer populations than other illicit drugs_-often face the greatest stigma (Ahern, Stuber, \& Galea, 2007).

Compounding the problem of knowledge at the amateur level is that though WADA's rules and mission apply to all levels of sport, much of the educational programming and information is targeted only at the elite level of the sport. Athletes often rely on self-education through unofficial sources such as the media or Internet, even other athletes (Erickson, McKenna, \& Backhouse, 2015; Johnson, Butryn, \& Masucci, 2013). Those at lower levels, such as the large and growing number of amateur runners, are technically governed by the rules but are rarely, if ever, tested for or formally educated about any potentially harmful or enhancing substances. Yet, they continue to bear the responsibility for managing their health risks and of continuing to work towards an everhealthier lifestyle.

Much debate around the regulation of substances in sport centers on health risk to the athlete. However, as Gleaves (2010) argued, there are reasons outside of health risk that some substances should be banned from sport, including protecting the continuity of, and the meaning derived from, the contesting of sport and maintaining the internal goods individuals derive from the process of engagement in sport. Further, because the rules of the sport prohibit some substances, their use 
may also be seen to violate the social contract - the "implicit consensual agreements between participants stating their shared interpretation and interest" (Harviainen \& Lieberoth, 2001, p. 529)that athletes enter when competing. The question becomes more complex when moving outside of overtly banned substances and into the topic of dietary supplements.

\section{Supplements}

Previous research on media and the supplement industry has argued niche and mainstream print and on-line media sources act as "robust sources for claimsmaking activities purported by sports nutrition supplement companies and industry experts" (Bailey, 2013, p. 1105).

Manufacturers can make claims about what benefits their products offer as long as they carry a disclaimer that the Food and Drug Administration (FDA) has not verified the claims. Highly troubling is the lack of oversight with regard to negative side effects resulting from use of these products (Cohen, 2012) as a result of the 1994 Dietary Supplement and Health Education Act (DSHEA) that allowed supplement manufacturers to market products without first demonstrating their safety (U.S. Public Law 103-417, 1994). Prior to the DSHEA, these products were more tightly controlled by the FDA for both effectiveness and safety (for a review of supplement regulations before 1994, see Kaczka, 1999). Due to the current state of lax regulation, it is left to the individual to judge the health risk and reward of supplements. At the same time healthist demands compel them to "choose" health and lifestyle aids, partly because it is "expected that prudent and responsible individuals will embrace the goods and services offered by the flourishing health industry as part of their reasonable service to themselves" (Ayo, 2012, p. 103).

The health risks of supplements are not unknown to all stakeholders in sport. Antidoping agencies have also issued warnings to athletes to beware of supplements, and USADA (2014) has a page on its website dedicated to the risks of supplements and a search function to determine if a product or substance has been banned. This is a passive service, however, requiring the athlete to proactively seek out information about the risks of supplements. In their review of studies on supplements used by athletes, Baume, Hellemans, and Saugy (2007) note that athletes believe in the potential enhancing effects of supplements and use them for performance purposes. One study of Serbian athletes found that $74 \%$ reported regular use of at least one supplement or OTC medication; $21.1 \%$ reported using six or more such products (Suzic Lazic et al., 2011). It is likely similar results would be found among American athletes given the widespread use of supplements and OTC medications among Americans generally.

Use of these products, though legal, can present some ethical dilemmas for athletes and regulators. A full review of the vast 
literature on the ethical debates around performance enhancement in sports is outside the scope of this article. However, much research has been conducted on many aspects of sports ethics and philosophy regarding topics including: the ethics of performance enhancement (e.g. Gleaves, 2010; Veber, 2014), the ethics of doping and anti-doping (e.g. Culbertson, 2005; Møller, 2009), fairness and sport (e.g. Carr, 2008), technology and sport ethics (e.g. Culbertson, 2009; Konig, 1995; Miah, 2004). Research with elite amateur cyclists - those amateurs closest to the professional ranksfound that some athletes drew comparisons between non-harmful PEDs and supplement use and empathized with professionals who compete as their livelihood (Outram \& Stewart, 2015). Indeed, researchers have argued that dietary supplements may act as "gateways" to doping for at-risk athletes (Backhouse, Whitaker, \& Petróczi, 2013); that media emphasis and attention to the supposed enhancing benefits of supplements may provide the basis for choosing a supplement product, rather than medical or scientific guidance (James, Naughton, \& Petróczi, 2010); and that contaminated substances may lead to positive doping tests (de Hon \& Coumons, 2007). Athletes, then, are caught between the healthist demands to use products that support their healthy, active lifestyles and the morally-laden imperative to avoid illness and the use of banned PEDs. Further, the slow pace of regulation of supplements means potentially dangerous substances can be accessed by at-risk groups (Denham, 2011). Evidence of how lax oversight of these products is found in the report by researchers that a methamphetamine analog was detected in the popular workout supplement Craze, undertaken by the authors after athletes tested positive for the banned stimulant in doping tests (Cohen, Travis, \& Venhuis, 2013). While the authors note that athletes may inadvertently use a banned substance for which they would be responsible for under the strict liability principle, the greater concern is the unknown effects of this analog on the athletes who use it, as tests on humans of this stimulant have never been performed (Cohen, Travis, \& Venhuis, 2013).

Though supplement manufacturers in the United States are required to report adverse events of supplements to the FDA, Cohen (2009) found that as many as 50,000 adverse events are estimated to occur annually but relatively few are reported, meaning a potential recall could not be issued. Harel, Harel, Wald, Mamdani, and Bell (2013) found that recalls are not necessarily carried out even when the FDA confirms contaminated supplements, meaning many supplements present health risks to athletes who may equate availability with safety. Maughan, Greenhaff, and Hespel (2011) warn that as athletes become more and more desensitized to taking and using supplements, it becomes imperative that they exercise caution in order to minimize health risks_-especially when 
using the types of novel supplements that lack institutional regulation on their safety. Again, the demands and responsibility to manage risk while pursuing an active, healthy lifestyle are squarely on the athletes themselves.

\section{Methods}

This qualitative study's approach generally coincided with grounded theory procedures and sought to understand the ways the participants viewed and experienced performance enhancement, both legal and non. As a member of the New York City running community as a runner and, later, a coach, it was necessary for me to bracket my own views, experiences, and assumptions of performance enhancement throughout the research and analysis process (Charmaz, 2006; Tufford \& Newman, 2010). This process of setting aside one's own biases in order to remain open to new or challenging information and issues allows for a more impartial analysis of the data. Rather than relying on my preconceptions, bracketing these out enabled me to gain a deeper understanding of the topic and participants.

Data were drawn from semi-structured interviews with New York City-based nonelite runners that were the basis of a larger project on non-elite runners, performance enhancement, and health. In New York City, the premier racing organization is New York Road Runners (NYRR), a non-profit organization that is responsible for directing the world's largest marathon and the largest membership. NYRR also hosts more than 50 racing events per year, though only a handful feature doping control testing. Often, these events also have no division between sexes or age groups during the event, though in many races prizes are awarded to winners of sex and age groups. Every participant in NYRR races must agree to follow the rules of competition as laid out by United States Track and Field, including anti-doping rules laid out by World Anti-Doping Agency (WADA) and enforced by the United States Anti-Doping Agency (USADA). Though runners must agree to abide by anti-doping regulations in order to participate they are generally given no further explanation or information about these rules other than a link to the governing bodies' websites.

Affiliation with or membership on a NYRR-governed club team was a prerequisite for participation. This requirement ensured the runners interacted at least minimally with other members of the local running community, had a motivation to race regularly as club teams compete for points in specific races throughout the year, and ensured that these participants had agreed to follow the rules of competition that include anti-doping regulations when registering for a NYRR race.

Compared with the demographic patterns documented by Running USA (2015) in road running generally, the participants in this study are similar in the following ways: only two of the runners in 
this study were non-white, all were middle or upper class, urban residents, and all but one had attended college. Participants ranged in age from 25 to 56, and 19 males and nine females were included. Most of the participants identified exclusively as runners, though some also identified as multi-sport athletes such as cyclists, triathletes, or swimmers. The sample diverged from broader road running patterns along the lines of sex and competitiveness. In general, more females than males participate in road running though this sample has almost twice as many male participants than female. This may be related to gendered notions of competitiveness, as studies of the gendered roles in sport have shown that female athletes are generally portrayed as cooperative while males are competitive (Daddario, 1994) and that males are expected to be competitive athletes while women are not (Cuneen \& Claussen, 1999). Recruitment was based on referrals from other competitive athletes and it is possible that the "competitive" descriptor resulted in runners viewing male non-elite runners as more appropriate for the study than females.

The competitive descriptor was included in an effort to limit the sample to a manageable size and recruit a sample that was similar in its type of participation. Runners may participate in their sport in various ways, including those who race with a focus on the performance, those who race for reasons other than performance (i.e. fun, social connection, personal "bucket" list experiences), and those who choose to forgo racing altogether. By recruiting only "competitive" runners, I was able to recruit a sample that included team-affiliated runners who trained and raced with goals related to improving performances or meeting specific personal goals. In my recruitment materials, I did not define "competitive" other than to specify the person must be active and run for a NYRRaffiliated team. I did not limit the sample by number of races run or number of years the individual had been running, as many competitive runners may focus on a small number of races per year or have recently begun running for performance. Since runners may meet the team membership and performance-centered racing requirements and still not place well at a races or be objectively successful relative to others, there was no requirement for how well a runner ranked within his or her own age group to be part of the sample. I also did not limit the sample to those who had knowledge of anti-doping policies and procedures, or of doping in general. The study was not intended to test how well non-elite runners understand anti-doping policies. Rather, the goal of the study was to explore how runners who compete seriously, yet are largely left out of the antidoping process, perceive doping and other performance enhancement and the ways in which they negotiate these issues in their own training.

Early in the data collection it became clear these athletes race quite seriously and 
many were relatively successful non-elite runners both within and outside of the New York City running scene. These runners represent a population different from both elite and less competitive non-elite runners. These runners rarely win races outright, but several consistently finish at the top of their respective five year age groups and others have raced across road racing distances as sub-elite runners-a distinction given to the tier of runners above the local competitive but below the professional elites. While this does limit the generalizability of the study, it does offer a view into the world of competitive, non-elite running.

Interview participants were recruited through a network sampling process beginning with my own position within the running community and working outward to up to five degrees of separation from myself. This distance from myself ensured participants differed from the initial participants that were from my own personal network and to provide a sufficient sample of the population, reducing the bias often found in snowball samples (Semaan, Lauby, \& Liebman, 2002). As a condition of taking part in the study, each participant provided contact information of any three non-elite runners who fit the study criteria, detailed above. Using this information I contacted each runner via email notifying him or her that another runner who had taken part in the study had recommended them for participation. This recruitment strategy resulted in 45 invitations to participate, from which 28 individuals agreed to take part in a semi-structured interview.

The semi-structured interview provided a map for the interview to follow, and also allowed for flexibility during the interview (Schensul \& LeCompte, 1999). This flexibility enabled asking follow-up questions or for elaboration on a related point not specifically addressed by the question. Following a prepared guide, I asked participants about their experiences with and perceptions of health, doping, and supplements, and their motivations for training and racing. In addition to basic demographic questions (e.g. age, profession), each participant was asked 17 standard questions that could then followed-up with non-standard questions based on the response. The standard questions were based on existing literature around the topic of doping. Based on literature demonstrating professional and semi-professional athletes' lack of knowledge of doping and anti-doping policies and procedures (Mottram, Chester, Atkinson, \& Goode, 2008), I avoided questions asking about specific definitions or policies in favor of those about their perceptions (i.e. "How do you define doping?" "Do you consider all performance enhancement to be doping? Why or why not?" "Do you consider all forms of cheating or dishonest participation the same? Why or why not?"). Due to the documented effects of socially desirable responding when asked about doping (Petróczi \& Nepusz, 2011), I avoided direct 
questions about their own use of PEDs or of knowledge of their peers' doping. The questions instead focused on hypothetical situations and questions about running in general (i.e. "Why do you think a runner would choose to dope?" "How pervasive do you think doping is at all levels of running?" "What would you do if you knew of a runner who was doping?"). While the questions would not yield any prevalence data for PED or supplement usage, they were geared towards the perceptions and experiences of the athletes themselves.

Data analysis followed the procedures of grounded theory (Charmaz, 2006) wherein concepts and theory are developed through data coding and analysis. The audio-recorded interviews were transcribed and data then coded using the qualitative analysis software Atlas.ti. An initial code list was developed based on the broad thematic categories around which the interviews were organized, including conceptualizations of doping, health, and ethics. The full code list was created through a second inductive and iterative coding process (Charmaz, 2006). Following the coding process, data were arranged into specific thematic categories, such as supplements, over-the-counter drug usage, and non-doping performance enhancement.

Because some of the participants mentioned the substances they use during their own training and racing cycles, the runners are presented here using pseudonyms to maintain confidentiality. As will be discussed below, the participants varied quite a bit in their knowledge of banned substances and supplements, as well as in their views of what substances are healthy. Both of these factors had implications for supplementation practices each undertook as part of their own healthy lifestyle.

\section{Knowledge}

The dearth of knowledge in response to the question "what is doping?" underscored how unclear the line between performance enhancing supplements, which are at the center of anti-doping efforts in sport, and supplements was among participants. Carol, a 28 year old runner, noted that she frequently came across news of potential PEDs: "You read about things like so-andso's coach told them to do this and it's not really a drug." Like Carol, many of the respondents' ideas were gleaned from media reports of elite athletes who had failed a doping test, the Internet, or from speaking with fellow runners and athletes about the latest doping scandal.

Several participants admitted that they were unclear on what doping was, such as 46year-old Sam:

On our level, the competitive athlete level, I'm not that cognizant of all the rules and drugs. I take caffeine, alcohol, and Advil. I'm pretty sure I'm not in violation, but I don't know. If a doctor prescribed eye drops and that's a steroid am I in violation? I don't know. 
Beyond understanding doping as bad, risky for health, and to be avoided, these nonelite runners have very limited knowledge of the range of substances that are banned and the potential harms non-banned substances may present. Sam also noted that he worried about the negative health impacts of some of his habits-such as the toll alcohol would have on his heart-but that he did his best to avoid anything he thought presented a risk to his health.

Importantly, for all of the participants, objective health concerns trumped concerns about winning when considering any type of performance enhancement. Danielle, 41, summed up this view saying:

I run but I do other things. It's not that important to me if I win a race....We do it [run] to be fit and healthy and I don't think it's [PED use] a healthy thing to do to your body.

Running is viewed as part of the process of health, while PED use is seen to potentially jeopardize those efforts. The value here is placed on health and the continual avoidance of any risk to that goal.

\section{Doping}

One of the misunderstandings about doping was that all banned substances had to necessarily impact performance in a substantial way. Walt, 40, considered doping "Anything that artificially enhances your performance." The use of masking agentsthose products or substances used to hide or mask the presence of PEDs in the body—or non-enhancing banned substances were generally not mentioned by most participants. The one exception was regarding marijuana, as Sam noted "Someone who smokes pot, are they a doper? I guess yes." This was even true of Sarah, a 39-year-old experienced runner and running coach, who described how she understood doping: "I guess my first reaction is taking any kind of substance that enhances performance." When pressed, Sarah noted that not all enhancing substances were necessarily doping, including the coffee she drank while we spoke, and that doping was specifically banned substances or "like blood doping."

Sarah's assumption is in line with the understanding that banned substances will make performances better or training easier. Like all but three of the other participants, she understood doping to require intent to cheat by the athlete. As Brian, 43, said "Yeah, it has to be systematic and intentional otherwise it's in that grey area." This "grey area" is when an athlete may unintentionally use a banned substance, which Brian noted he does not consider doping.

The participants did believe that within their own daily practices of health they were acting properly and conforming to antidoping regulations, as they understand them. German, 41, described his own routine:

I take Vitamin D but that doesn't help me with training. I take an allergy pill because I have allergies. Outside of that, I try to eat fruits and vegetables and get 
nutrients and be overall healthy...The only supplements I take are what's on race day and those aren't supplements really. It's just the nutrition you need in powder form.

German sees his supplement use as part of improving and maintaining his health, not for enhancing his performance. Even his use of allergy pills did not cause him concern, despite several such products containing ingredients that are indeed banned by WADA (WADA, 2015b). However, many revealed that they do not fully understand either the entirety of the list of substances banned in competition or the logic that underpins these regulations. Brian rhetorically asked, "I mean, who even knows what's on the list?" This lack of clarity is likely due to the fact that none of the respondents had ever been exposed to formal anti-doping education.

Calvin also admitted to not having ever read the list of banned substances, but drew on his medical background to elaborate on what he saw as the defining characteristics of unacceptable PEDs:

I would say it is basically taking some type of substance that would give you an unfair advantage over other people. An advantage that is more than just training hard. Some type of hormone or pill that could make your response to training greater than just regular physiologic response.

He was clear that substances or methods could be performance enhancing without necessarily being considered doping. He was also clear that PEDs would allow an athlete to increase training volume and intensity while recovering at the same rate or faster than what could be achieved without such a substance, such as anabolic steroids. Though I noted during the interview that not all banned substances had such an effect, Calvin saw the distinction between allowable supplements and unallowable PEDs as being based on the physiological reaction to a substance. Effectiveness was the basis for doping in this view.

Even as a marathon runner who has won or placed in several races (though never given an anti-doping test), 37-year-old Carlo, also reported being unclear on what he thought constituted doping versus other forms of enhancement, except for the use of injections:

I think it's more injecting yourself with - or I'm not sure to say injecting, but taking some sort of foreign substance or taking, you know, like blood doping, adding something; more blood to your system to increase your ability to, like, exchange oxygen or even like, when running you know, the recovery. So you know, hGH - and I don't know if runners really take $\mathrm{hGH}$ or marathoners, but I'm sure like blood doping and EPO to increase your blood volume and things like that, yeah. Similarly, 40-year-old Stan thought doping included:

Shooting some chemicals in your blood, or giving your blood more oxygen. I think they're taking blood out and then 
shooting chemicals into in to give it more oxygen...Taking hGH for example. Doing testosterone injections, I consider doping. Or an artificial product that would be an enhancement and are not natural.

For Carlo and Stan, doping specifically meant blood doping or injecting PEDs that would alter one's blood profile and result in a significantly improved performance. Injecting a substance, especially one considered "artificial," into the body was viewed as one of the clear indications that something might not be acceptable. The risks of using injected substances outside a medical setting presented a clear line between what is doping and what could be allowable.

Early in his interview, Carlo noted that he did not think banned PEDs were necessarily bad and could potentially be useful for runners. He reiterated his view by offering that blood doping or EPO could actually aid recovery for runners: "If anything they [doping athletes] are probably, you know, if you are able to recover faster you're probably actually helping your body." This comment underscores the fine line between what is understood as healthy and what is considered harmful. The participants sought to remain in compliance with the rules of the sport, as far as they understood them, and with the demands of health culture. One way the participants engaged with their health was through the use of supplements.

\section{Supplements}

With the exception of one, all of the participants responded that they regularly use some form of supplementation, most commonly in the form of vitamin supplements, isolated proteins, or electrolyte replacement products such as GU or Gatorade type products. Gillian, 39, reported taking "probiotics and a multivitamin" daily. Roger, 37, reported using "fish oil everyday, vitamin D everyday, multi-vitamin, whey protein everyday." Similarly, most responded that they use or have used some form of OTC pain or cold/flu medication, many routinely, such as 28-year-old Mike: "I have a longstanding relationship with Advil... at times I've relied on them with 12 a day." "These products were used for routine health maintenance, such as preventing dehydration in training, promoting overall health and improved immunity, or for managing physical discomfort related to training.

Several respondents also indicated that they actively sought out supplements to aid in their training and recovery, such as Carrie, 31, who reported using a recovery supplement: "I mean I take Endurox to recover, but that's still legal." In each case the respondent drew a distinction between banned substances and whatever form of supplementation or medication they used, casting the former as unacceptable and antihealth and the latter as acceptable and prohealth. Overall, the good-healthy/badunhealthy dichotomy appeared to dominate 
much of the participants' thinking about doping.

Wyatt, 54, was one of the more outspoken, strict anti-doping respondents. He was, however, in favor of using supplements. He explained his regimen, set out by a local doctor:

I did a detox program with juicing, endurance, weights, very rigorous diet, lots of supplements, stress relief, meditation...I took a lot of supplements, but none would've put me on the WADA list...I've taken some things that are claimed to be performance enhancing, but independently from athletics. I think they have health benefits, but not for the performance enhancement. Gaining potential pro-health benefits was Wyatt's motivation for undertaking his supplementation regimen. He was clear in pointing out he was not seeking a performance benefit from this medicallybased detoxification program, which also included blood testing and analysis, though did acknowledge that such a benefit may indeed exist. He distinguished between the allowable health enhancing effects of a program centered on supplements and what he considers an unacceptable performance enhancing benefit from banned PEDs. For Wyatt, and the several other respondents who drew a similar distinction, any unsolicited performance enhancement from a supplement would be a "happy coincidence" even if unintentional. Since dietary supplements are widely used and accepted by both runners and non-runners, any benefit derived from their use is allowable, fortunate, and even desirable.

Indeed, runners like Wyatt see supplements as an investment in their health. Most interviewees, such as 28-yearold Henry, were quick to acknowledge that they indeed seek performance enhancement when taking supplements:

When I first started running I tried everything off the shelves to see if they had any effect in performance enhancement or muscle or how much mileage I could handle, anything I read about I would just try it.

Henry based his decisions on what to try based on their availability in retail stores or information found through running websites and forums. He was willing to try anything to benefit performance, assuming minimal risk to his health of such trials. Similarly, Carrie based her regard for the safety of a product on its context. Carrie reflects that she doesn't worry about what she is taking because "I know that what I'm doing is legal and from GNC and in Runner's World magazine." As with Henry, Carrie assumes the products she sees advertised in Runner's World magazine or sold at the supplement retail chain GNC do not present any objective risk to her health, but instead her consumption of such products may benefit her performance and health in some way. Both Henry and Carrie perceive a low risk of such products based on their relationship to or appearance with trusted media, brands, or individuals. 
The willingness to try a variety of substances found within a running context did not automatically remove all perceived risk. Brian described his history of supplementation experiments in search of performance benefits:

I was sponsored by [supplement company] and I take their stuff...At expos you try things... hornet vomit... Over the years it's [personal usage] toned down to multi, vitamin $\mathrm{C}$, and fish oil, and I don't take that consistently...I mean, supplements are basically thrown together, but it's hardly whole food... Who knows what it is? Brian raises the question about the contents and safety of many supplements. Athletes are often admonished to buy supplements only from "reputable" companies, but determining and tracking down which manufacturers are reputable can be difficult. While he does continue to use supplements, Brian acknowledged the lack of transparency regarding the contents of many supplements.

Like Henry and Carrie, Brian's use of supplements is normalized by the amount of products he is surrounded with at sports expos he attends, in stores he shops in, and supplied by his sponsors. Normalization of these substances within the running community lessens the perception of risk. Dietary supplements are not only viewed as less risky than banned PEDs, they are also viewed positively as a healthy practice. Because he is inundated with such products promising to boost his health and his performances, Brian views these products as acceptable training aids. As a result, he takes the safety of these products for granted despite his own critique of the lack of information and regulation of such supplements.

Though most of the participants were willing and sometimes eager to use supplements, they were not willing to take what they perceived as higher cost risks with their health. Henry was willing to use any supplements he could find for performance enhancement, but was unwilling to knowingly use a banned substance. When asked why he would not engage in doping he responded:

Potential for bodily harm. I mean if you're risk adverse, fearful of the general stigma against it. You do the cost-benefit analysis and decide the satisfaction or potential monetary compensation isn't valuable enough to offset the health cost or the stigma of being a cheat then you wouldn't do that. I think most people are pretty riskaverse. There isn't a lot of great evidence that says it's [doping] good for our long-term health, I mean why put your self at that great of risk? Henry avoids risk-taking behaviors in the absence of evidence that such risk could potentially benefit health. Notably, an absence of evidence indicating such a risk is anti-health does not have the opposite effect that would lead him to try banned substances. The official ban, therefore, seems to imply some type of health risk and 
runners, like Henry, who avoid this type of risk would then avoid banned substances. Henry, unlike Brian who expressed concern at the questionable contents of supplements and other non-banned substances, perceives a negligible health risk in taking non-banned supplements and, as noted above, is not averse to their consumption and use by him or other runners.

\section{Discussion}

This research delineates the ways competitive, non-elite runners engage in processes of healthicization and how their participation in competitive sport works to shape their behaviors and beliefs. The nonelite runners in this study engaged in specific practices they viewed as furthering the goal of becoming or remaining healthy and moral individuals, including avoiding risky PEDs and using "safe" supplements to enhance both health and performance. They viewed doping and supplement use as distinct practices with specific motivations, the former to win competitions and the latter to bolster health. Despite the documented problems of dietary supplements and their regulation for safety or effectiveness, the participants continued to view them as safe and healthy. This appears inconsistent with healthist demands to avoid risks to one's health, but demonstrates that runners understand health and risk within the context of their sport and their identities as moral citizens. Running and potential racing success are ways to show how fit one is - both in terms of health and citizenship. The desire to protect that identity offers a partial explanation for why runners seek to avoid knowingly consuming banned substances, but will use questionable supplements in their routines: supplements are a "safe" way to enhance and/or mitigate the negative effects of intense training, meaning their use functions as a daily practice of health.

Most participants thought doping was limited to the substances and methods most commonly detected and reported upon when elite athletes have tested positive for PEDs: anabolic steroids, Erythropoietin (EPO), blood doping involving banking ones own blood, and human growth hormone $(\mathrm{hGH})$. Any substance requiring injection done outside a medical setting presented a line between more and less risky PEDs, similar to recent findings among amateur cyclists (Outram \& Stewart, 2015). The notion that an injected substance was likely banned or harmful if done outside of a medical setting is likely related to fears and associations of both the anabolic steroid injecting athlete (Monaghan, 2001; Beamish, 2011) and with those of injection drug users of illicit narcotics such as heroin (Ahern, Stuber, \& Galea, 2007). While they did go out of their way to avoid such substances in order to protect health, they were unaware of other doping agents, as well as the potential risks presented by substances that had not received media coverage. This suggests that these runners were unaware of the nuances of anti-doping regulations, but also that they may overlook banned and 
potentially dangerous substances taken unintentionally. In this way, the current participants were behaving in ways counter to the imperative of health culture to always be aware of your personal health risks despite their active pursuit of health. Further, many felt that as long as they were not actively seeking to enhance their performance through substances, they were not in violation of the rules or risking health. However, doping and the associated health risks do not require intent (Pluim, 2008) as when athletes are sanctioned for accidental ingestion of a banned substance (Henning \& Dimeo, 2015).

Though most participants agreed that using substances banned in racing present a high level of risk to individual health, they generally had only partial knowledge of doping and banned substances. This finding was consistent with previous surveys of elite athletes, including some who are regularly given doping tests (Johnson, Butryn, \& Masucci, 2013; Mottram et al., 2008). In the current case, this may be partially explained by the lack of formal anti-doping education, and the participants' reliance on media and other runners for information. This type of self-education was consistent with recent research findings on protective factors against doping (Erickson, McKenna, \& Backhouse, 2015).

Though non-elite runners are generally not subject to anti-doping tests, rarely win any significant prizes, and are rarely the focus of media coverage, that does not preclude them from seeking out ways to improve their running performances. Most participants purchased and used dietary supplements and OTC medications to improvement health and/or enhance performance. For most participants, supplements presented a loophole for potentially gaining a performance enhancement while remaining within the letter of sports law, as they understand it. This acceptability allows non-elite runners to maintain their identity as good/healthy runners because they have avoided substances banned from sports, as they can continue to claim they are avoiding risks to their health as well as performing good sportsmanship.

The widespread use of dietary supplements among the participants points to a complex issue for runners' health. With the exception of only three participants, the runners in this study saw dietary

supplements as a low risk way to promote health and potentially aid performance within what they understood as the rules of the sport. This sense of security is understandable given the important role the FDA has in regulating food and medicine. Instead, a product's availability appears to overshadow printed warnings that the FDA has not approved a supplement. Relying on coaches, other runners, or Internet sources for information is not useful when none of the parties has been educated on antidoping policy or the health implications of many available supplements and OTC products. Thus, the vast array of sources and products available to runners can be 
difficult to negotiate. This task becomes even more difficult when considered against the backdrop of a health culture that requires them to take full responsibility for their health.

\section{Limitations}

This study is limited in that the sample includes more male participants than female. The current sample includes only $32 \%$ women, contrary to the broader road racing demographics where women outnumber men $57 \%$ to $43 \%$, respectively (Running USA, 2015). As previously noted, this difference may result from gendered notions of competitiveness where women are viewed as generally less competitive in comparison to their male counterparts. It is possible that participants viewed male runners as more "competitive" than female runners, and that this view was reflected in who they chose to refer for participation. A second limitation is that this study only focused on competitive and team-affiliated non-elite runners' views and experiences of doping and dietary supplements. While neither limitation should diminish the importance of their views as a group, they may limit the generalizability of this group to the less competitive non-elite runners that make up the majority of road races. Future research into less competitive amateur runners is important to better understand the intersections of regulation, substances, and health for a greater section of the growing running population. Any future studies should also employ sampling methods that ensure women are represented in proportion to their general participation rates in road races. Further, future research into runners' usage and perceptions of PEDs and supplements should examine if differences between runners emerge along such lines as gender, age, racing frequency, training volume, age group (or overall) placing and ranking. This research would likely require a larger sample than the one used in the current project.

\section{Conclusion}

The non-elite runners in this study share a healthicized ethos. They view their participation, supplementation, and trainingrelated habits as an endeavor towards health. Health culture demands that individuals have relevant medical knowledge and an understanding of their individual risk profile. Indeed, the participants take the information they receive via the media or others in the running community and attempt to apply it to their own process of health. However, these interpretations of what is or is not either doping or healthy, as well as bad or good, are often shaped by one's identity as a healthy runner.

Despite the demonstrated risk of using supplements, such products are presented to runners and others in the opposite way: that individuals risk their health by not using them. As such, there is no need to question the risks of their use for either health or performance, as would be the case with banned PEDs. Purchasing and using supplements is then part of the daily 
practice of health, through which runners demonstrate their fit as healthy citizens. The supplement-using runner, then, is responsible, constantly aware of and managing her health through training and correct supplementation in accordance with the goals of health culture. Consumption of these products, then, is a central part of the process of health. The irony is that it is these same products that may also undermine a runner's health.

Whether or not they are effective for performance enhancement, the safety and contents of dietary supplements is questionable (Pipe \& Ayotte, 2002). These products, while legal, may be crosscontaminated with banned substances or other potentially harmful ingredients not included on the product labels. Labels do not necessarily report all potential ingredients that may make their way into supplements-either accidently through sharing close manufacturing quarters with other products, or intentionally by manufacturers who add banned performance enhancers to the products to produce the effects sought by the consumer - that put athletes at risk for unanticipated negative side effects, such as allergic reactions (Cohen, 2009). The participants were not wholly unaware of the risks presented by supplements. However, their use was so widely accepted that their use became a normal part of training for most. In this environment, especially when runners rely on a range of sources for information, a runner could conflate availability or effectiveness with safety and healthfulness.

Increasing athlete awareness of the potential risk of using unverified supplements could help runners make better decisions when considering using a substance for either health or performance enhancement. Anti-doping agencies and the governing bodies for running and athletics could address both the knowledge gaps and health risks by expanding educational programming regarding banned and nonbanned substances to include non-elite runners. Educational programs adapted from the model proposed by Backhouse, McKenna, and Patterson (2009) that includes tailoring the presentation to the specific audience, skill development, and reinforced through follow-up presentations could effectively target non-elite runners and reflect their experiences with training and racing. Such programs should also be sensitive the requirements of health culture faced by these adult athletes.

Given the widespread use of supplements generally and how the risks of some well-known doping agents have been sensationalized (López, 2013; 2014), it is perhaps unsurprising that many would not question the safety of a product they may have been encouraged to use by the media, other runners, or a coach. However, in assuming supplements are safe, allowable, and healthy, many runners may be taking inadvertent risks with their health. It is likely that Claire Squires felt relatively safe in using the supplement Jack3D for a boost 
during the later miles of the London Marathon (Hamilton, 2013). Her resulting

death is a stark reminder that availability ensures neither safety nor healthfulness when considering supplements. 


\section{References}

Ahern, J., Stuber, J., \& Galea, S. (2007).

Stigma, discrimination and the health of illicit drug users. Drug and Alcohol Dependence, 88(2), 188-196.

Ayo, N. (2012). Understanding health promotion in a neoliberal climate and the making of health conscious citizens. Critical Public Health, 22(1), 99-105.

Backhouse, S. H., Whitaker, L., \& Petróczi, A. (2013). Gateway to doping? Supplement use in the context of preferred competitive situations, doping attitude, beliefs, and norms. Scandinavian Journal of Medicine \& Science in Sports, 23(2), 244-252.

Backhouse, S., McKenna, J., \& Patterson, L. (2009). Prevention through education: a review of current international social science literature. A focus on the prevention of bullying, tobacco, alcohol and social drug use in children, adolescents and young adults. Retrieved from https://www.ncjrs.gov/App/Publica tions $/$ abstract.aspx?ID $=263102$.

Bailey, B. J. (2013). Ethnopharmacology and male bodybuilders' lived experience with consuming sports nutrition in Canada. Sport in Society, 16(9), 11051119.

Baume, N., Hellemans, L., \& Saugy, M. (2007). Guide to over-the-counter sports supplements for athletes. International Sport Medicine Journal, 8(1), 2-10.
Beamish, R. (2011). Steroids: A new look at performance-enhancing drugs. Santa Barbara: Praeger.

Carr, C. L. (2008). Fairness and performance enhancement in sport. Journal of the Philosophy of Sport, 35(2), 193-207.

Charmaz, K. (2006). Constructing grounded theory: A practical guide through qualitative analysis. London: Sage.

Cohen, P. A. (2009). American roulettecontaminated dietary supplements. New England Journal of Medicine, 361(16), 1523-1525.

Cohen, P. A. (2012). Assessing supplement safety-the FDA's controversial proposal. New England Journal of Medicine, 366(5), 389-391.

Cohen, P. A., Travis, J. C., \& Venhuis, B. J. (2013). A methamphetamine analog (N, $\alpha$-diethylphenylethylamine) identified in a mainstream dietary supplement. Drug Testing and Analysis. DOI 10.1002/dta.1578

Conrad, P. (1994). Wellness as virtue: Morality and the pursuit of health. Culture, Medicine and Psychiatry, 18, 385-401.

Crawford, R. (2006). Health as a meaningful social practice. Health, 10(4), 401-420.

Culbertson, L. (2005). The paradox of bad faith and elite competitive sport. Journal of the Philosophy of Sport, 32(1), 65-86.

Culbertson, L. (2009). Genetic enhancement in the dark. Journal of the Philosophy of Sport, 36(2), 140-151. 
Cuneen, J., \& Claussen, C. L. (1999).

Gender protrayals in sports-product point-of-purchase advertising. Women in Sport \& Physical Activity Journal, 8(2), 73.

Daddario, G. (1994). Chilly scenes of the 1992 winter games: the mass media and the marginalization of female athletes. Sociology of Sport Journal, 11(3), 275-288.

de Hon, O., \& Coumans, B. (2007). The continuing story of nutritional supplements and doping infractions. British Journal of Sports Medicine, 41(11), 800-805.

Denham, B. E. (2011). When science, politics, and policy collide: On the regulation of anabolic-androgenic steroids, steroid precursors, and "dietary supplements" in the United States. Journal of Sport \& Social Issues, 35(1), 3-21.

Erickson, K., McKenna, J., \& Backhouse, S. H. (2015). A qualitative analysis of the factors that protect athletes against doping in sport. Psychology of Sport and Exercise, 16, 149-155.

Gahache, J., Bailey, R., Burt, V., Hughes, J., Yetley, E., Dwyer, J., Picciano, M. F., McDowell, M., \& Sempos, C. (2011). Dietary supplement use among u.s. adults has increased since NHANES III (1988-1994). NCHS Data Brief, 61.

Gillick, M. R. (1984). Health promotion, jogging, and the pursuit of the moral life. Journal of Health Politics, Policy and Law, 9(3), 369-387.
Gleaves, J. (2010). No harm, no foul? Justifying bans on safe performanceenhancing drugs. Sport, Ethics and Philosophy, 4(3), 269-283.

Guthman, J., \& DuPuis, M. (2006). Embodying neoliberalism: economy, culture, and the politics of fat. Environment and Planning D, 24(3), 427.

Hamilton, M. 2013. Marathoner's death highlights risk of some supplements. Runner's World. Accessed April 2, 2013.

Harel, Z., Harel, S., Wald, R., Mamdani, M., \& Bell, C. M. (2013). The frequency and characteristics of dietary supplement recalls in the United States. JAMA Internal Medicine, 173(10), 929-930.

Harris Interactive. (2002). Widespread ignorance of regulation and labeling of vitamins, minerals and food supplements. Health Care News 2(6), $1-5$.

Harviainen, J. T., \& Lieberoth, A. (2011). Similarity of social information processes in games and rituals: Magical interfaces. Simulation \& Gaming, 43(4), 528-549.

Henning, A. D. (2014). Run for Health: Health(icization), Supplements, and Doping in Non-Elite Road Running. Doctoral Dissertation. Available from

http://works.gc.cuny.edu/etd/223/

Henning, A. D., \& Dimeo, P. (2015).

Questions of fairness and anti-doping in US cycling: The contrasting 
experiences of professionals and amateurs. Drugs: Education, Prevention and Policy, 1-10.

Hochstetler, D. (2007). Can we experience significance on a treadmill? In M. Austin (Ed.), Running and philosophy: A marathon for the mind. Malden, MA: Blackwell Publishing.

Hutchinson, A. (2015, April 8). Beyond fitness. Runner's World. Retrieved from

http://www.runnersworld.com/swea t-science/beyond-fitness

Isin, E.F. (2004). The neurotic citizen. Citizenship Studies 8(3), 217-235.

James, R., Naughton, D. P., \& Petróczi, A. (2010). Promoting functional foods as acceptable alternatives to doping: potential for information-based social marketing approach. Journal of the International Society of Sports Nutrition, 7(1), 1-11.

Johnson, J., Butryn, T., \& Masucci, M. A. (2013). A focus group analysis of the US and Canadian female triathletes' knowledge of doping. Sport in Society, 16(5), 654-671.

Kaczka, K. A. (1999). From herbal Prozac to Mark McGwire's tonic: How the Dietary Supplement Health and Education Act changed the regulatory landscape for health products. Journal of Contemporary Health Law \& Policy, 16(2), 463.

König, E. (1995). Criticism of doping: The nihilistic side of technological sport and the antiquated view of sport ethics. International Review for the Sociology of Sport, 30(3-4), 247-260. Lavrence, C., \& Lozanski, K. (2014). “This is not your practice life": Lululemon and the neoliberal governance of self. Canadian Review of Sociology/Revue Canadienne de Sociologie, 51(1), 76-94.

López, B. (2013). Creating fear: The social construction of human Growth Hormone as a dangerous doping drug. International Review for the Sociology of Sport, 48(2), 220-237.

López, B. (2014). Creating fear: the 'doping deaths', risk communication and the anti-doping campaign. International Journal of Sport Policy and Politics, 6(2), 213-225.

Maughan, R. J., Greenhaff, P. L., \& Hespel, P. (2011). Dietary supplements for athletes: emerging trends and recurring themes. Journal of Sports Sciences, 29(sup1), S57-S66.

Miah, A. (2004). Genetically modified athletes: Biomedical ethics, gene doping and sport. New York, NY: Routledge.

Møller, V. (2009). The ethics of doping and antidoping: Redeeming the soul of sport?. New York, NY: Routledge.

Monaghan, L. F. (2001). Bodybuilding, Drugs And Risk. London, UK: Routledge. Mottram, D., Chester, N., Atkinson, G., \& Goode, D. (2008). Athletes' knowledge and views on OTC medication. International Journal of Sports Medicine, 29, 851-855.

National Institutes of Health (NIH). (2011). Dietary supplements: Background 
information. Available from:

http://ods.od.nih.gov/factsheets/Di

etarySupplements-

HealthProfessional/

Outram, S. M., \& Stewart, B. (2015).

Condemning and condoning: Elite amateur cyclists' perspectives on drug use and professional cycling. International Journal of Drug Policy.

Pipe, A., \& Ayotte, C. (2002). Nutritional supplements and doping. Clinical Journal of Sport Medicine 12, 245-249.

Pluim, B. (2008). A doping sinner is not always a cheat. British Journal of Sports Medicine, 42(7), 549-550.

Reynolds, G. (2014, December 3). Run to stay young. The New York Times.

Retrieved from well.blogs.nytimes.com/2014/12/03 /run-to-stay-young/

Roberts, W. O. (2015, July 6). Physical activity keeps you young. Runner's World. Retrieved from www.runnersworld.com/ask-thesports-doc/physical-activity-keepsyou-young

Rose, N. (1999). Powers of freedom: Reframing political thought. Cambridge: Cambridge University Press.

Running USA. (2015). 2015 State of the sport: U.S. race trends. Retrieved from

http://www.runningusa.org/2015state-of-sport-us-trends

Semaan, S., Lauby, J., \& Liebman, J. (2002). Street and network sampling in evaluation studies of HIV risk- reduction interventions. AIDS

Reviews 4(4), 213-223.

Schensul, J. J., \& LeCompte, M. D. (1999).

Enhanced ethnographic methods:

Audiovisual techniques, focused group

interviews, and elicitation techniques.

Walnut Creek, Calif.: Altamira Press.

Shipway, R., \& Holloway, I. (2010).

Running free: Embracing a healthy lifestyle through distance running. Perspectives in Public Health, 130(6), 270-276.

Shipway, R., Holloway, I., \& Jones, I. (2013). Organisations, practices, actors, and events: Exploring inside the distance running social world. International Review for the Sociology of Sport, 48(3), 259-276.

Suzic Lazic, J., Dikic, N., Radivojevic, N., Mazic, S., Radovanovic, D., Mitrovic, N., Lazic, M., Zivanic, S., \& Suzic., S. (2011). Dietary supplements and medications in elite sport Polypharmacy or real need? Scandinavian Journal of Medicine and Science in Sports 21, 260-267

United States Anti-Doping Agency (USADA). (2014). Supplement 411: Realize, recognize, reduce. Retrieved from http://www.usada.org/substances/s upplement-411/

U.S. Public Law 103-417, 103rd Congress, 25 October 1994. Dietary supplement health and education act of 1994. 
Van Thuyne, W., Van Eenoo, P., \&

Delbeke, F. T. (2006). Nutritional

supplements: prevalence of use and

contamination with doping agents.

Nutrition Research Reviews, 19(1), 147158.

Veber, M. (2014). The coercion argument against performance-enhancing drugs. Journal of the Philosophy of Sport, 41(2), 267-277.

Well Blog. (2014, March 12). What running can do for your heart. New York Times. Retrieved from well.blogs.nytimes.com/2014/03/12 /what- running-can-do-for-theheart/

Williams, S.J. (2002). Sleep and health: Sociological reflections on the dormant society." Health: An Interdisciplinary Journal for the Social Study of Health, Illness and Medicine, 6(2), 173-200.

World Anti-Doping Agency (WADAa). (2015). World anti-doping code. Retrieved from https://www.wadaama.org/en/resources/thecode/world-anti-doping-code

World Anti-Doping Agency (WADAb). (2015). List of prohibited substances and methods. Retrieved from https://www.wadaama.org/en/resources/sciencemedicine/prohibited-list 